Article

\title{
Benzyl Furanones and Pyrones from the Marine-Derived Fungus Aspergillus terreus Induced by Chemical Epigenetic Modification
}

\author{
Jing-Shuai $\mathrm{Wu}^{1,2}$, Xiao-Hui Shi ${ }^{1,2}$, Ya-Hui Zhang ${ }^{1,2}$, Chang-Lun Shao ${ }^{1,2} \oplus$, Xiu-Mei Fu ${ }^{1,2}$, \\ Xin $\mathrm{Li}^{1,2}$, Guang-Shan Yao ${ }^{1,2,3, *}$ and Chang-Yun Wang ${ }^{1,2, *}$ \\ 1 Key Laboratory of Marine Drugs, The Ministry of Education of China, School of Medicine and Pharmacy, \\ Institute of Evolution \& Marine Biodiversity, Ocean University of China, Qingdao 266003, China; \\ wujingshuai0110@sina.cn (J.-S.W.); 13061461893@163.com (X.-H.S.); 15689932652@163.com (Y.-H.Z.); \\ shaochanglun@163.com (C.-L.S.); fuxiumei92@163.com (X.-M.F.); lixin8962@ouc.edu.cn (X.L.) \\ 2 Laboratory for Marine Drugs and Bioproducts, Qingdao National Laboratory for Marine Science and \\ Technology, Qingdao 266237, China \\ 3 Institute of Oceanography, Minjiang University, Fuzhou 350108, China \\ * Correspondence: ygshan@126.com (G.-S.Y.); changyun@ouc.edu.cn (C.-Y.W.); \\ Tel.: +86-0591-8378-9471 (G.-S.Y.); +86-0532-8203-1536 (C.-Y.W.)
}

Academic Editor: Vincenzo Piccialli

Received: 7 August 2020; Accepted: 27 August 2020; Published: 27 August 2020

\begin{abstract}
Chemical epigenetic modification on a marine-derived fungus Aspergillus terreus RA2905 using a histone deacetylase inhibitor, suberoylanilide hydroxamic acid (SAHA), resulted in a significantly changed metabolic profile. A chemical investigation of its ethyl acetate (EtOAc) extract led to the isolation of a racemate of benzyl furanone racemate $( \pm)-\mathbf{1}$, which further separated chirally as a pair of new enantiomers, (+)- and (-)-asperfuranone (1), together with two new benzyl pyrones, asperpyranones A (2) and B (3). Their structures were elucidated by analysis of the comprehensive spectroscopic data, including one-dimensional (1D) and two-dimensional (2D) NMR, and HRESIMS. The absolute configurations were determined by electronic circular dichroism (ECD) calculation and single-crystal X-ray crystallographic experiment. The structures with benzyl furanone or benzyl pyrone skeletons were discovered from natural products for the first time. Compounds $( \pm)-\mathbf{1},(+)-\mathbf{1},(-)-\mathbf{1}$, and $\mathbf{2}$ displayed the antifungal activities against Candida albicans with MIC values of 32, 16, 64, and $64 \mu \mathrm{g} / \mathrm{mL}$ and PTP1B inhibitory activities with the $\mathrm{IC}_{50}$ values of $45.79,17.32,35.50$, and $42.32 \mu \mathrm{M}$, respectively. Compound 2 exhibited antibacterial activity against Pseudomonas aeruginosa with the MIC value of $32 \mu \mathrm{g} / \mathrm{mL}$.
\end{abstract}

Keywords: marine-derived fungus; Aspergillus terreus; chemical epigenetic modification; benzyl furanone; benzyl pyrone

\section{Introduction}

Marine fungi have proven to be a prolific source of structurally novel and biologically active secondary metabolites [1]. Among them, the widespread fungi of Aspergillus genus have been extensively investigated for decades due to their chemical diversities and the respected pharmacological activities of secondary metabolites, such as polyketones, xanthones, alkaloids, cyclic peptides, and terpenes [2-4]. However, a significant number of genome sequencing analysis of Aspergillus species have revealed that most biosynthetic gene clusters are silent or expressed at low levels under standard laboratory conditions, indicating that the capacity of these fungal strains to produce natural products is far more than we anticipated [5]. In recent years, chemical epigenetic manipulation has been widely used as an effective and handy approach to turn on the cryptic biosynthetic pathways in Aspergillus species to obtain induced secondary metabolites. For example, chemical epigenetic manipulation was applied to 
the marine algicolous fungus Aspergillus terreus OUCMDZ-2739 with $10 \mu \mathrm{M}$ histone deacetylase inhibitor, trichostatin A (TSA), resulting in the production of four new meroterpenoids [6].The marine-derived fungus A. terreus PF26 was cultured with $900 \mu \mathrm{M}$ histone deacetylase inhibitor, suberoylanilide hydroxamic acid (SAHA), inducing the enhancement of the production of (+)-terrein [7]. A sea sediment-derived fungus Aspergillus sydowii was treated with a DNA methyltransferase inhibitor, 5-azacytidine (5-Aza), leading to the isolation of a series of new bisabolene-type sesquiterpenoids [8]. Therefore, chemical epigenetic manipulation exhibited tremendous potential for excavating cryptic secondary metabolites from marine-derived Aspergillus species.

In recent years, during our efforts to explore new bioactive marine natural products [9], chemical epigenetic manipulation has been applied to marine-derived fungi to mine their potential ability to produce metabolic products [9-14]. In our previous work, a series of thiodiketopiperazines and 3,4-dihydroisocoumarin derivatives were isolated from the starch liquid culture of $A$. terreus RA2905 derived from sea hare Aplysia pulmonica [15]. In the present study, in order to tap the metabolic potential of this fungal strain, chemical epigenetic modifiers were applied to activate its cryptic secondary biosynthetic pathways. The metabolic profile was changed by cultivating with SAHA, detected by HPLC. The chemical investigation of its ethyl acetate (EtOAc) extract resulted in the isolation of a racemate of benzyl furanone, which further separated chirally as a pair of new enantiomers, and two new benzyl pyrones. Herein, we report the epigenetic manipulation on this fungus, and the isolation, structural determination, and bioactivity evaluation of the induced products.

\section{Results}

The chemical epigenetic manipulation on A. terreus RA2905 was conducted in a starch liquid medium with the conditions of $180 \mathrm{rpm}, 28^{\circ} \mathrm{C}$, for 7 days, cultivated with histone deacetylase inhibitors and DNA methyltransferase inhibitors in different concentrations $(1-1000 \mu \mathrm{M})$. The fungal culture in the same medium without an inhibitor was used as the control. As a result, in the HPLC profiles, much more remarkable peaks (20-30 min) emerged in the fungal culture treated with $100 \mu \mathrm{M}$ SAHA as compared with the control (Figure 1). The production of terrein was significantly increased about nine-fold, while the production of butyrolactones was decreased, especially butyrolactone II. Subsequently, a scaled-up fermentation with $100 \mu \mathrm{M}$ SAHA was carried out. The EtOAc extract of the culture was separated by using column chromatography, semi-preparative and chiral HPLC, resulting in the isolation of a racemate of benzyl furanone racemate, $( \pm)-\mathbf{1}$, which further separated chirally as a pair of new enantiomers, $(+)$ - and (-)-asperfuranone (1), and two benzyl pyrones, asperpyranones A (2) and B (3) (Figure 2).

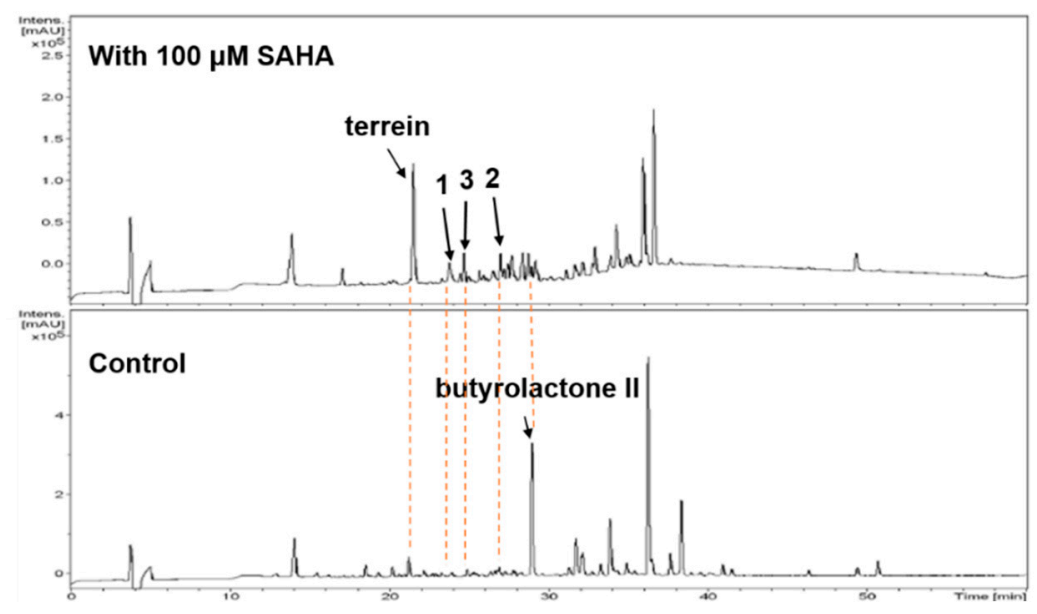

Figure 1. HPLC detection on ethyl acetate (EtOAc) extracts of Aspergillus terreus RA2905 with $100 \mu \mathrm{M}$ SAHA. 

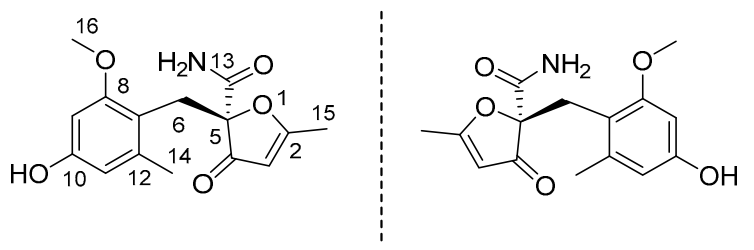

$( \pm)-1$<smiles>COc1cc(O)cc(C)c1Cc1c(O)cc(C)oc1=O</smiles>

2<smiles>COc1cc(O)cc(C)c1Cc1c(O)cc(CC(O)C(F)(F)F)oc1=O</smiles>

Figure 2. Chemical structures of compounds.

\subsection{Structure Elucidation}

Compound 1 was obtained as a white crystal. The molecular formula of $\mathrm{C}_{15} \mathrm{H}_{17} \mathrm{O}_{5} \mathrm{~N}$ was deduced by HRESIMS spectrum, indicating eight degrees of unsaturation. The stretch signals at 3300, 2892, $2845,2350,1709,1607,1452,1385$, and $1025 \mathrm{~cm}^{-1}$ in the IR spectrum suggested the presence of hydroxyl/amino, carbonyl, and aromatic groups in 1 . The ${ }^{1} \mathrm{H}$ NMR spectrum showed the proton signals for 1,2,3,5-tetrasubstituted benzene ring $\left(\delta_{\mathrm{H}} 6.14, \mathrm{~d}, J=2.3 \mathrm{~Hz}\right.$ and $\left.6.12, \mathrm{~d}, J=2.3 \mathrm{~Hz}\right)$, three active hydrogen signals $\left(\delta_{\mathrm{H}} 9.21,7.31\right.$, and 7.23), one hydrogen signal for double bond $\left(\delta_{\mathrm{H}} 5.32\right)$, one methoxyl $\left(\delta_{\mathrm{H}}\right.$ 3.57), one methylene $\left(\delta_{\mathrm{H}} 3.25\right.$ and 3.19), and two methyl $\left(\delta_{\mathrm{H}} 2.11\right.$ and 2.02) (Table 1$)$. A total of 15 carbon atoms were observed in the ${ }^{13} \mathrm{C}$ NMR spectrum, including three methyls (one oxygenated), one methylene, one quaternary carbon, eight olefinic carbons (three protonated and two oxygenated), and two carbonyls, as distinguished by the HSQC spectrum. The HMBC correlations from H-6 to C-8/C-12, from $\mathrm{H}-16$ to $\mathrm{C}-8$, and from $\mathrm{H}-14$ to $\mathrm{C}-7 / \mathrm{C}-11$ revealed the structure of a benzyl group, combining with spectroscopic characteristics of the 1,2,3,5-tetrasubstituted benzene ring (Figure 3). In addition, a spin system of $C-6-C-5-C-4-C-3-C-2-C-15$ was established according to the HMBC correlations from $\mathrm{H}-3$ to $\mathrm{C}-2 / \mathrm{C}-4 / \mathrm{C}-5 / \mathrm{C}-15$, from $\mathrm{H}-6$ to $\mathrm{C}-4 / \mathrm{C}-5 / \mathrm{C}-13$, and from $\mathrm{H}-15$ to $\mathrm{C}-2 / \mathrm{C}-3$. As the presence of two carbonyl groups, one aromatic ring and one double bond in the molecule occupied seven degrees of unsaturation, compound 1 should contain one furan ring formed by C-2 and C- 5 in consideration of their carbon chemical shifts $\left(\delta_{C} 189.8\right.$ for C-2, $\delta_{C} 91.4$ for C-5). The HMBC correlations from H-6 to $\mathrm{C}-13$ and $13-\mathrm{NH}_{2}$ to $\mathrm{C}-5 / \mathrm{C}-13$ indicated that the $\mathrm{NH}_{2}$ group was anchored to the carbonyl carbon, $\mathrm{C}-13$, and this carbonyl was located at the quaternary carbon, C-5. Thus, the planar structure of 1 was established.
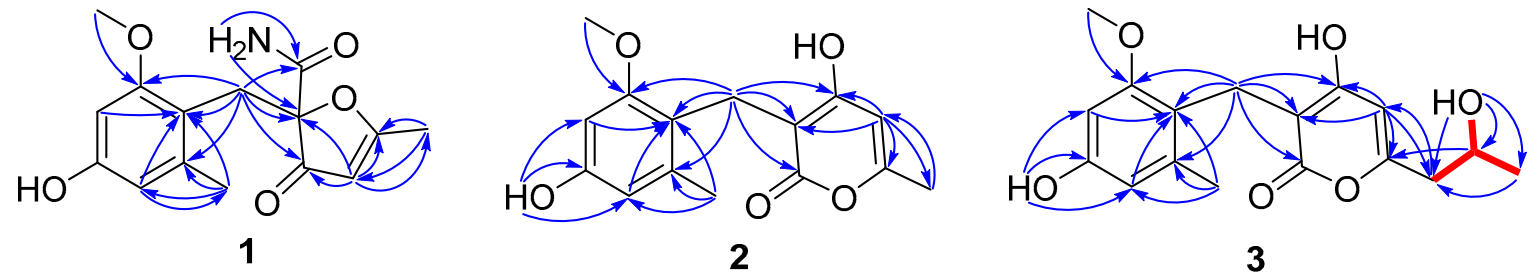

\section{$-{ }^{1} \mathrm{H}-{ }^{1} \mathrm{H}$ COSY correlation $\frown \mathrm{HMBC}$ correlation}

Figure 3. The ${ }^{1} \mathrm{H}-{ }^{1} \mathrm{H}$ COSY and key HMBC correlations of $\mathbf{1}$ and $\mathbf{3}$. 
Table 1. ${ }^{1} \mathrm{H}$ NMR $(500 \mathrm{MHz})$ and ${ }^{13} \mathrm{C}$ NMR $(125 \mathrm{MHz})$ data for 1 in DMSO- $d_{6}$.

\begin{tabular}{ccc}
\hline Position & $\delta_{\mathrm{C}, \text { Type }}$ & $\delta_{\mathbf{H}}(J \mathbf{~ i n ~ H z})$ \\
\hline 2 & $189.8, \mathrm{C}$ & \\
3 & $102.0, \mathrm{CH}$ & $5.32, \mathrm{~s}$ \\
4 & $198.9, \mathrm{C}$ & \\
5 & $91.4, \mathrm{C}$ & $3.25, \mathrm{~d}(14.2)$ \\
6 & $30.1, \mathrm{CH}_{2}$ & $3.19, \mathrm{~d}(14.2)$ \\
& & \\
7 & $111.7, \mathrm{C}$ & \\
8 & $159.2, \mathrm{C}$ & $6.14, \mathrm{~d}(2.3)$ \\
9 & $96.3, \mathrm{CH}$ & \\
10 & $156.7, \mathrm{C}$ & \\
11 & $108.8, \mathrm{CH}$ & \\
12 & $139.3, \mathrm{C}$ & $2.11, \mathrm{~d}(2.3)$ \\
13 & $166.7, \mathrm{C}$ & $2.02, \mathrm{~s}$ \\
14 & $20.0, \mathrm{CH}_{3}$ & $3.57, \mathrm{~s}$ \\
15 & $16.2, \mathrm{CH}_{3}$ & $9.21, \mathrm{~s}$ \\
16 & $55.0, \mathrm{CH}_{3}$ & $7.23, \mathrm{~s}$ \\
$10-\mathrm{OH}$ & & $7.31, \mathrm{~s}$ \\
$13-\mathrm{NH} \mathrm{H}_{2}$ & & \\
& & \\
\hline
\end{tabular}

After many attempts, a suitable crystal of $\mathbf{1}$ was obtained by evaporating slowly in a mixed solvent of $\mathrm{CH}_{2} \mathrm{Cl}_{2}$ /acetone/MeOH (1:1:1). However, the space group of $\mathrm{C} 2 / \mathrm{c}$ of its crystal, combined with its optical value of 0 , compound 1 was suspected to be a racemate. Then, by using a chiral chromatographic column, a pair of enantiomers, $(+)$ - and (-)-1, were separated with the peak area ratio of 1:1 (Figure 4).
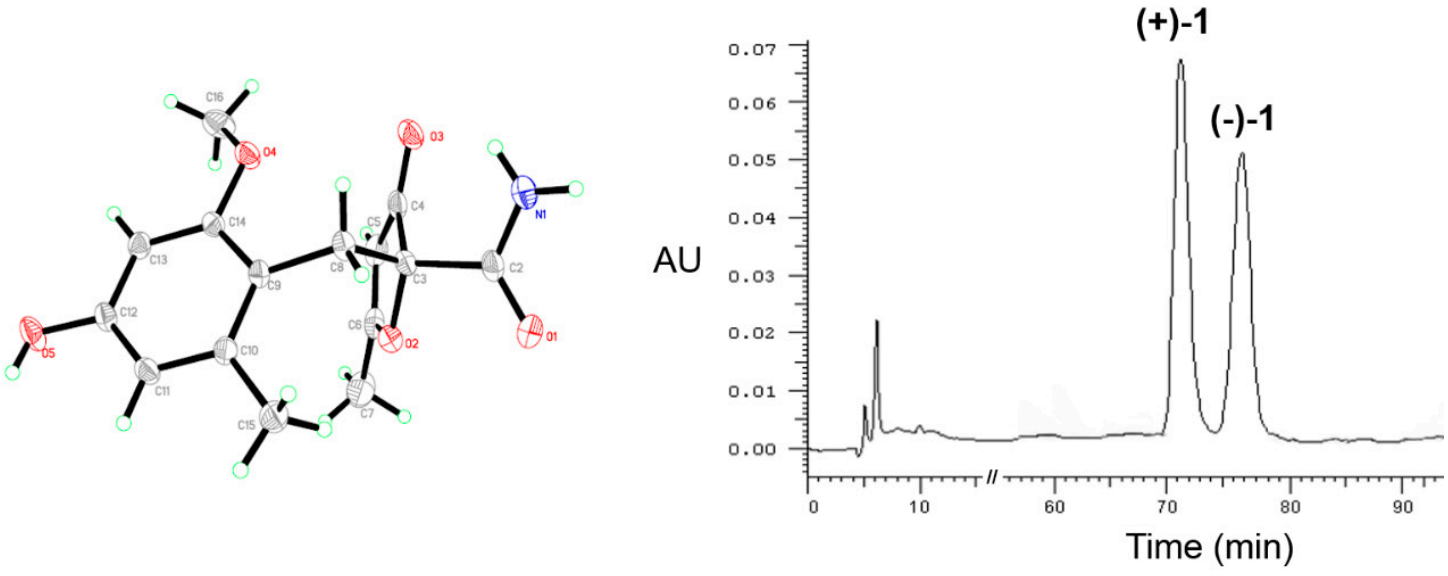

Figure 4. X-ray ORTEP drawing of $\mathbf{1}$ and chiral HPLC chromatogram of $( \pm)-\mathbf{1}$.

In order to determine the absolute configurations of (+)- and (-)-1, the calculations for their electronic circular dichroism (ECD) spectra were performed by using the time-dependent density functional theory (TDDFT) at the B3LYP/6-311+G(d,p) level in MeOH (Table S1). The results showed that the calculated ECD spectra of (+)- and (-)-1 were in accordance with their experimental spectra with negative and positive Cotton effects in the range of 240-340 nm, respectively (Figure 5). Thus, (+)- and (-)-1 were defined with absolute configurations as $2 R$ and $2 S$, and named as (+)- and $(-)$-asperfuranone, respectively. 


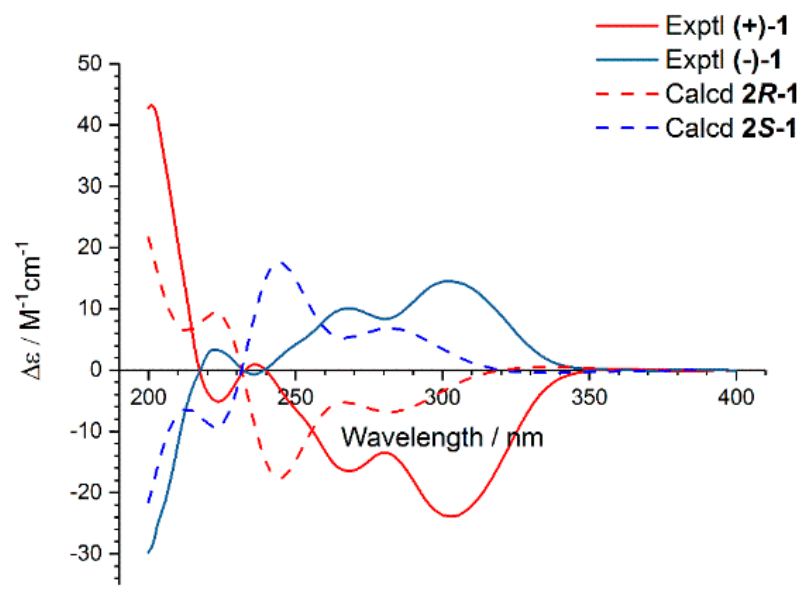

Figure 5. Experimental and calculated electronic circular dichroism (ECD) spectra of (+)-1 and (-)-1 in $\mathrm{MeOH}$.

Compound 2 was determined to be $\mathrm{C}_{15} \mathrm{H}_{16} \mathrm{O}_{5}$ with eight degrees of unsaturation on the basis of HRESIMS data. By careful analysis of its ${ }^{1} \mathrm{H}$ and ${ }^{13} \mathrm{C}$ NMR data, the spectroscopic characteristics of the benzyl group (from C-7 to C-13) in 2 were revealed, which were the same as those of compound 1 (Table 2). One methoxyl and one methyl were located at C-9 and C-13 of the benzyl group, respectively, based on the HMBC correlations from H-16 to C-9, and from $\mathrm{H}-14$ to $\mathrm{C}-8 / \mathrm{C}-12 / \mathrm{C}-13$. A spin system of C-15-C-2-C-3-C-4-C-5-C-6 was established base on the HMBC correlations from $\mathrm{H}-3$ to $\mathrm{C}-2 / \mathrm{C}-4 / \mathrm{C}-5 / \mathrm{C}-15$ and from $\mathrm{H}-15$ to $\mathrm{C}-2 / \mathrm{C}-3$ (Figure 3). As the presence of one carbonyl group, one aromatic ring and two double bonds in the molecule occupied seven degrees of unsaturation, compound 2 should contain one pyran ring formed between C-2 and C-6 in consideration of their carbon chemical shifts $\left(\delta_{C} 164.9\right.$ for $C-2, \delta_{C} 164.3$ for C-6). The HMBC correlations from H-7 to C-4/C-5/C-6 suggested that the benzyl group was anchored to C-5 of the pyran ring. One methyl was connected to C-6 in the pyran ring based on the HMBC correlations from $\mathrm{H}-3$ to $\mathrm{C}-15$ and from $\mathrm{H}-15$ to C-3. Thus, the structure of $\mathbf{2}$ was established, and named as asperpyranone A.

Table 2. ${ }^{1} \mathrm{H}$ NMR (500 MHz) and ${ }^{13} \mathrm{C}$ NMR (125 MHz) data for 2 and 3 in DMSO- $d_{6}$.

\begin{tabular}{|c|c|c|c|c|}
\hline \multirow{2}{*}{ Position } & \multicolumn{2}{|c|}{2} & \multicolumn{2}{|c|}{3} \\
\hline & $\delta_{\mathrm{C}}$, Type & $\delta_{\mathrm{H}}(J$ in $\mathrm{Hz})$ & $\delta_{\mathrm{C}}$, Type & $\delta_{\mathrm{H}}(J$ in $\mathrm{Hz})$ \\
\hline 2 & $164.9, \mathrm{C}$ & & $160.4, \mathrm{C}$ & \\
\hline 3 & $100.1, \mathrm{CH}$ & $5.94, \mathrm{~s}$ & $100.9, \mathrm{CH}$ & $5.96, \mathrm{~s}$ \\
\hline 4 & $159.3, \mathrm{C}$ & & $164.4, \mathrm{C}$ & \\
\hline 5 & $100.5, \mathrm{C}$ & & $100.8, C$ & \\
\hline 6 & $164.3, \mathrm{C}$ & & $164.7, \mathrm{C}$ & \\
\hline 7 & 19.6, $\mathrm{CH}_{2}$ & 3.46, brs & 19.6, $\mathrm{CH}_{2}$ & 3.46 , brs \\
\hline 8 & 117.0, C & & 117.0, C & \\
\hline 9 & $158.6, \mathrm{C}$ & & $158.6, \mathrm{C}$ & \\
\hline 10 & $96.8, \mathrm{CH}$ & $6.15, \mathrm{~d}(2.3)$ & $96.8, \mathrm{CH}$ & $6.16, \mathrm{~d}(2.3)$ \\
\hline 11 & $155.7, \mathrm{C}$ & & $155.7, \mathrm{C}$ & \\
\hline 12 & $108.9, \mathrm{CH}$ & $6.10, \mathrm{~d}(2.3)$ & $108.9, \mathrm{CH}$ & $6.10, \mathrm{~d}(2.3)$ \\
\hline 13 & 138.1, C & & $138.1, \mathrm{C}$ & \\
\hline 14 & $19.9, \mathrm{CH}_{3}$ & $2.17, \mathrm{~s}$ & $19.9, \mathrm{CH}_{3}$ & $2.16, \mathrm{~s}$ \\
\hline 15 & $19.2, \mathrm{CH}_{3}$ & $2.10, \mathrm{~s}$ & $42.7, \mathrm{CH}_{2}$ & $2.39, \mathrm{~d}(6.4)$ \\
\hline 16 & $55.3, \mathrm{CH}_{3}$ & $3.61, \mathrm{~s}$ & $64.1, \mathrm{CH}$ & $3.87, \mathrm{~m}$ \\
\hline 17 & & & 23.4, $\mathrm{CH}_{3}$ & $1.07, \mathrm{~d}(6.1)$ \\
\hline 18 & & & $55.4, \mathrm{CH}_{3}$ & $3.61, \mathrm{~s}$ \\
\hline $\mathrm{OH}-11$ & & $9.03, \mathrm{~s}$ & & $9.03, \mathrm{~s}$ \\
\hline $\mathrm{OH}-16$ & & & & $4.77, \mathrm{~d}(5.1)$ \\
\hline
\end{tabular}


Compound 3 was given as $\mathrm{C}_{17} \mathrm{H}_{20} \mathrm{O}_{6}$ with eight degrees of unsaturation based on the HRESIMS data. The ${ }^{1} \mathrm{H}$ and ${ }^{13} \mathrm{C}$ NMR spectroscopic characteristics of 3 were similar to those of $\mathbf{2}$, which revealed the presence of benzyl pyranone structure (Table 2). The main difference was that the methyl $\left(\delta_{\mathrm{H}} 2.10\right.$, $\left.\delta_{\mathrm{C}} 19.2\right)$ in 2 was replaced by an isopropanol group $\left(\delta_{\mathrm{H}} 2.39, \delta_{\mathrm{C}} 42.7\right.$ for $\mathrm{CH}_{2}-15 ; \delta_{\mathrm{H}} 3.87, \delta_{\mathrm{C}} 64.1$ for $\mathrm{CH}-16 ; \delta_{\mathrm{H}} 1.07, \delta_{\mathrm{C}} 23.4$ for $\left.\mathrm{CH}_{3}-17\right)$ in 3 , which was verified by the corresponding ${ }^{1} \mathrm{H}-{ }^{1} \mathrm{H}$ COSY of $\mathrm{H}-15 / \mathrm{H}-16 / \mathrm{H}-17$ and $\mathrm{H}-16 / 16-\mathrm{OH}$, and HMBC correlations from 16-OH to C-15/C-16/C-17 and from $\mathrm{H}-17$ to $\mathrm{C}-15$ (Figure 3). The isopropanol was located at C-2 based on the HMBC correlations from $\mathrm{H}-3$ to $\mathrm{C}-15$, from $\mathrm{H}-15$ to $\mathrm{C}-3$, and from $\mathrm{H}-16$ to $\mathrm{C}-2$. At first, an unsuccessful attempt was made to assign the absolute configuration of C-16 by Mosher's method, possibly due to the influence of hydroxyl groups on the C-11 of aromatic ring or C-4 of double bond in 3. Furthermore, the calculation of ECD of 16S-3 and 16R-3 was performed (Table S1). The results showed that the experimental ECD spectrum was in accordance with the calculated spectrum of 16S-3 with the negative Cotton effects at 210 and $280 \mathrm{~nm}$ (Figure 6). Thus, compound 3 was tentatively assigned with the absolute configuration of $16 S$, and named as asperpyranone B.

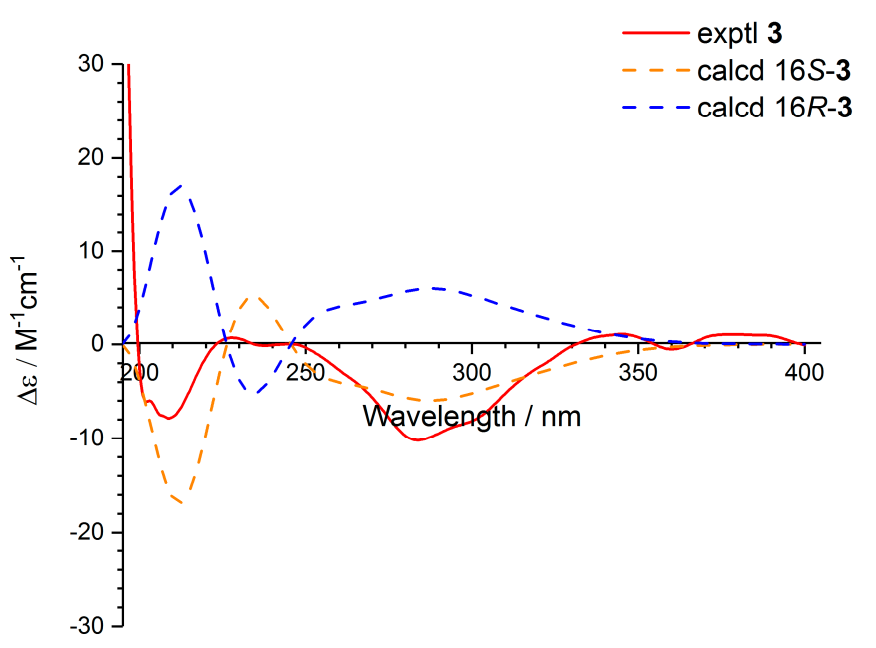

Figure 6. Experimental and calculated ECD spectra of 3 in $\mathrm{MeOH}$.

The benzyl furanone and pyrone metabolites were supposed to be produced in this strain through the fungal PKS biosynthetic pathway activated by epigenetic modification (Figure 7). The structure of benzyl, intermediate A, was synthesized with condensation and cyclization reactions from one acetyl-CoA and three malonyl-CoA. One malonyl-CoA was added into the intermediate A to produce intermediate $\mathrm{B}$, which was further fused with two malonyl-CoA to afford intermediate $\mathrm{C}$ through Claisen condensation, reduction, and rearrangement reactions. Heterocyclization along with double-bond isomerizations provided the intermediate $\mathrm{D}$ with the furanone ring [16]. A $\mathrm{NH}_{2}$ group was reacted with carboxyl to give compound 1. The intermediate B fused with two malonyl-CoA to give intermediate $\mathrm{E}$. When the hydroxyl group on the terminal double bond of intermediate $\mathrm{E}$ was condensed with the carboxyl, the pyrone ring was formed to yield intermediate F. The following ketone-enol tautomerization afforded compound 2 . While two malonyl-CoA were added into the intermediate B resulting in the production of intermediate $\mathrm{G}$ with Claisen condensation, reduction, and rearrangement reactions. Similarly, the condensation between hydroxyl on the terminal double bond and the carboxyl on intermediate $G$, and the subsequent ketone-enol tautomerization formed intermediate I. The carbonyl of intermediate I was reduced to hydroxyl to yield compound 3. 


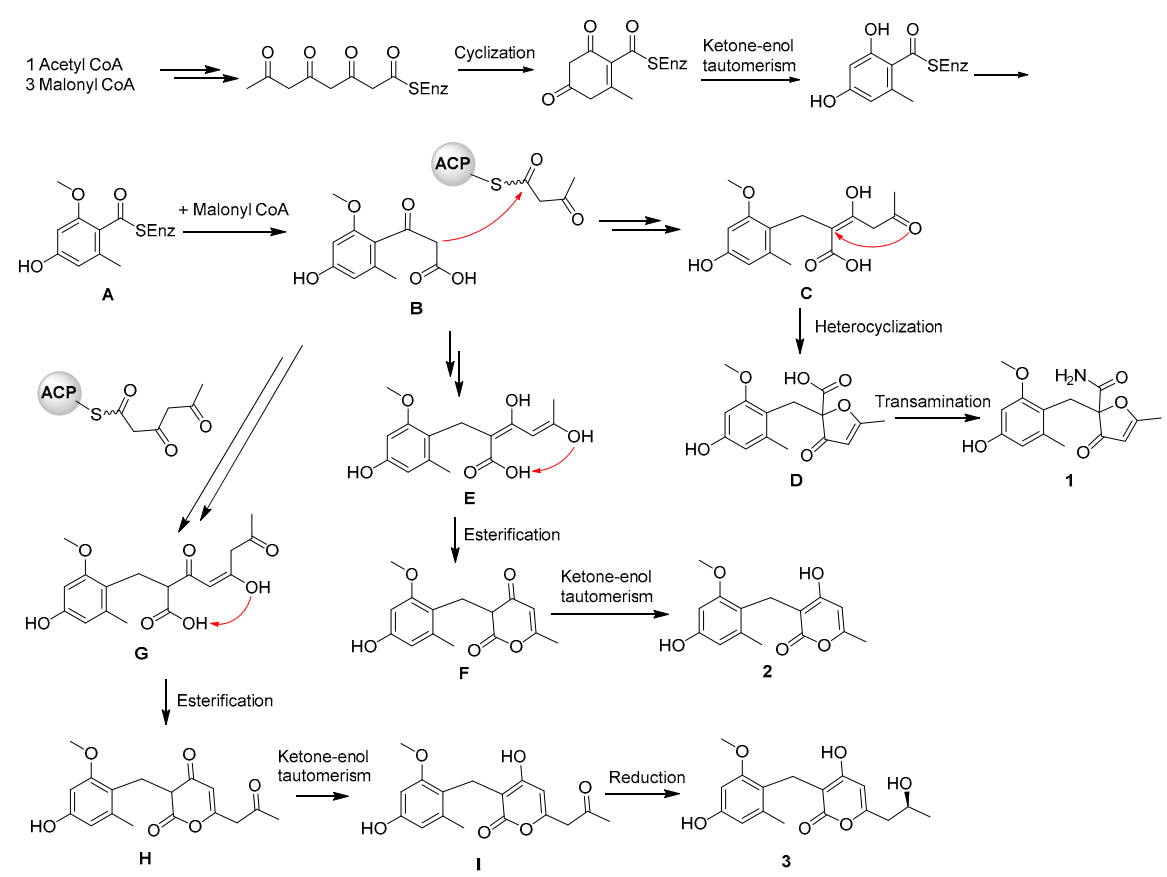

Figure 7. The biosynthetic pathway of benzyl furanone (1) and pyrones (2 and 3).

\subsection{Bioassays}

All of the isolated compounds were tested for their antifungal, antibacterial, cytotoxic, and PTP1B inhibitory activities (Table S2). Compounds $( \pm)-\mathbf{1},(+)-\mathbf{1},(-)-\mathbf{1}$, and $\mathbf{2}$ displayed the antifungal activities against Candida albicans with the MIC values of 32, 16, 64, and $64 \mu \mathrm{g} / \mathrm{mL}(0.5 \mu \mathrm{g} / \mathrm{mL}$ for positive control amphotericin B). Compounds 2 and 3 exhibited antibacterial activities against Pseudomonas aeruginosa ATCC 27853 with the MIC values of 32 and $128 \mu \mathrm{g} / \mathrm{mL}$, respectively $(1 \mu \mathrm{g} / \mathrm{mL}$ for positive control vancomycin). Compounds ( $( \pm)-\mathbf{1},(+)-\mathbf{1},(-)-\mathbf{1}$, and $\mathbf{2}$ also showed PTP1B inhibitory activities with the $\mathrm{IC}_{50}$ values of $45.79,17.32,35.50$, and $42.32 \mu \mathrm{M}$, respectively ( $4 \mu \mathrm{M}$ for positive control oleanolic acid). All of the tested compounds showed no cytotoxicity. Interestingly, the isomers (+)-1 and (-)-1 displayed differentiated effects, of which (+)-1 exhibited more active than (-)-1 in antifungal and PTP1B inhibitory activities.

\section{Materials and Methods}

\subsection{Instrumentation}

Optical rotations were measured on a JASCO P-1020 digital polarimeter (Jasco Corp., Tokyo, Japan). UV spectra were recorded on a HITACHI UH 5300 UV spectrophotometer (Hitachi, Tokyo, Japan). The ECD data were acquired on a J-815-150S Circular Dichroism spectrometer (JASCO Electric Co., Ltd., Tokyo, Japan). The IR spectra were recorded on a Nicolet-Nexus-470 spectrometer (Thermo Electron Co., Madison, WI, USA) using KBr pellets. The NMR spectra were acquired by a JEOL JEM-ECP NMR spectrometer (500 MHz for ${ }^{1} \mathrm{H}$ and $125 \mathrm{MHz}$ for ${ }^{13} \mathrm{C}$, JEOL, Tokyo, Japan), using TMS as an internal standard. HREIMS were measured on a Thermo MAT95XP high resolution mass spectrometer (Thermo Fisher Scientific, Bremen, Germany), and EIMS spectra on a Thermo DSQ EImass spectrometer (Thermo Fisher Scientific, Bremen, Germany). Single-crystal X-ray crystallographic analysis was performed on an Agilent Xcalibur Eos Gemini diffractometer (Agilent Technologies, Yarnton, England). Samples were analyzed on a Hitachi L-2000 HPLC system coupled with a Hitachi L-2455 photodiode array detector and using a $\mathrm{C}_{18}$ column (Kromasil $250 \times 4.6 \mathrm{~mm}, 5 \mu \mathrm{m}$ ). The semi-prepared HPLC was conducted by a semi-prepared $\mathrm{C}_{18}$ column (Kromasil $250 \times 10 \mathrm{~mm}, 5 \mu \mathrm{m}$ ). The chiral HPLC chromatographic isolation of compound 1 was conducted using the semi-prepared 5-TBB column (Kromasil $250 \times 10 \mathrm{~mm}, 5$ 
$\mu \mathrm{m})$. Silica gel (Qing Dao Hai Yang Chemical Group Co., China; 300-400 mesh) and Sephadex LH-20 (Amersham Biosciences) were used for column chromatography (CC). Precoated silica gel plates (Yan Tai Zi Fu Chemical Group Co., China; G60, F-254) were used for thin-layer chromatography. PTP1B (human recombinant) was purchased from Abcam (ab51277).

\subsection{Fungal Material}

The fungal strain was isolated from a piece of fresh tissue from the inner part of the sea hare Aplysia pulmonica, collected from the Weizhou coral reefs in the South China Sea during April 2010. The fungus was identified as Aspergillus terreus based on the sequence analysis (GenBank accession no. MK611650) of the ITS region of the rRNA gene, as described previously [15]. This fungal strain was deposited in the Key Laboratory of Marine Drugs, Ministry of Education of China, School of Medicine and Pharmacy, Ocean University of China, Qingdao, China.

\subsection{Extraction and Isolation}

Sixty $500 \mathrm{~mL}$ Erlenmeyer flasks of the fungal strain were cultivated in the starch liquid medium (soluble starch $10 \mathrm{~g} / \mathrm{L}$, peptone $1 \mathrm{~g} / \mathrm{L}$, artificial sea salt $30 \mathrm{~g} / \mathrm{L}, 200 \mathrm{~mL}$ each flask) by adding 100 $\mu \mathrm{M}$ SAHA with the conditions of $150 \mathrm{rpm}, 28^{\circ} \mathrm{C}$, for 7 days. The fermentation broth and mycelia were separated through cheesecloth and extracted repeatedly with equal amounts of ethyl acetate (EtOAc) for three times, respectively. The extracts were combined and evaporated in vacuo to afford an EtOAc extract (11.2 g). The EtOAc extract was isolated on silica gel column chromatography (CC) using a step gradient elution with petroleum ether/acetone $(10: 1$ to $1: 4, v / v)$ to provide six fractions (Fr.1-Fr.6). Fr.4 was separated by Sephadex LH-20 CC eluted with $\mathrm{CH}_{2} \mathrm{Cl}_{2} / \mathrm{MeOH}(1: 1, v / v)$ and the semi-preparative HPLC with $\mathrm{MeOH} / \mathrm{H}_{2} \mathrm{O}(55: 45, v / v)$ to give compounds 1 (4.2 $\left.\mathrm{mg}\right), 2$ (3.5 mg), and 3 $(1.9 \mathrm{mg})$. Compound 1 was subjected to the chiral chromatographic HPLC with isopropanol/ n-hexane $(10: 90, v / v)$ as the elution system to provide $(+)-\mathbf{1}(1.2 \mathrm{mg})$ and (-)-1 (0.9 $\mathrm{mg})$.

Asperfuranone (1). white crystal; $[\alpha]_{\mathrm{D}}^{20} 0\left(c\right.$ 0.5, MeOH); UV (MeOH) $\lambda_{\max }(\log \varepsilon) 221(1.41), 249$ (0.63) nm; IR (KBr) $v_{\max } 3300,2892,2845,2350,1709,1607,1452,1385,1025 \mathrm{~cm}^{-1} ;{ }^{1} \mathrm{H} \mathrm{NMR}(500 \mathrm{MHz}$, DMSO- $\left.d_{6}\right)$, and ${ }^{13} \mathrm{C}$ NMR (125 MHz, DMSO- $\left.d_{6}\right)$, see Table 1 ; HRESIMS $m / z 292.1182[\mathrm{M}+\mathrm{H}]^{+}$(calcd for $\mathrm{C}_{15} \mathrm{H}_{18} \mathrm{O}_{5} \mathrm{~N}, 292.1179$ ), $m / z 314.0998[\mathrm{M}+\mathrm{Na}]^{+}$(calcd for $\mathrm{C}_{15} \mathrm{H}_{17} \mathrm{O}_{5} \mathrm{NNa}$, 314.0999).

Crystal data for $1: \mathrm{C}_{15} \mathrm{H}_{17} \mathrm{O}_{5} \mathrm{~N}, M r=291.11$, monoclinic, $a=14.5365(4) \AA, b=11.9873(2) \AA, c=$ 17.8891(4) $\AA, \alpha=90.00^{\circ}, \beta=115.707(3)^{\circ}, \gamma=90.00^{\circ}, V=2808.72(12) \AA^{3}$, space group $C 2 / c, Z=8, D x=$ $1.378 \mathrm{mg} / \mathrm{m}^{3}, \mu(\mathrm{Cu} \mathrm{K \alpha})=0.896 \mathrm{~mm}^{-1}$, and $F(000)=1232$. Crystal dimensions: $0.08 \times 0.07 \times 0.07 \mathrm{~mm}^{3}$. Independent reflections: $4781 / 2518\left(R_{\text {int }}=0.0142\right)$. The final $R 1$ value was $0.0386, w R 2=0.1019(I>$ $2 \sigma(I))$. Crystallographic data of $\mathbf{1}$ have been deposited in the Cambridge Crystallographic Data Centre (deposition number CCDC 1984035).

(+)-Asperfuranone (1). $[\alpha]_{\mathrm{D}}^{20}+178.3($ c 0.5, $\mathrm{MeOH}) ; \mathrm{ECD}(\mathrm{MeOH}) \lambda_{\max }(\Delta \varepsilon) 264(-10.3), 301(-13.5)$.

(-)-Asperfuranone (1). $[\alpha]_{\mathrm{D}}^{20}-178.3$ ( $\left.0.5, \mathrm{MeOH}\right)$; ECD $(\mathrm{MeOH}) \lambda_{\max }(\Delta \varepsilon) 264$ (10.3), 301 (13.5).

Asperpyranone A (2). yellow solid; UV (MeOH) $\lambda_{\max }(\log \varepsilon) 220$ (1.75), 271 (1.01) nm; IR (KBr) $v_{\max }$ $3648,2358,1734,1681,1651,1540,1393,1203,1093 \mathrm{~cm}^{-1} ;{ }^{1} \mathrm{H}$ NMR (500 MHz, DMSO- $\left.d_{6}\right)$ and ${ }^{13} \mathrm{C} \mathrm{NMR}$ (125 MHz, DMSO- $d_{6}$ ), see Table 2; HRESIMS $m / z 275.0927[\mathrm{M}-\mathrm{H}]^{-}$(calcd for $\left.\mathrm{C}_{15} \mathrm{H}_{15} \mathrm{O}_{5}, 275.0925\right)$.

Asperpyranone B (3). yellow solid; $[\alpha]_{\mathrm{D}}^{20}+8.1$ (c 0.5, MeOH); UV (MeOH) $\lambda_{\max }(\log \varepsilon) 220(1.95)$, 263 (0.97) nm; IR (KBr) $v_{\max } 3748,3650,2360,1734,1684,1651,1540,1510,1208,1140 \mathrm{~cm}^{-1}$; ${ }^{1} \mathrm{H} \mathrm{NMR}$ $\left(500 \mathrm{MHz}, \mathrm{DMSO}-d_{6}\right)$ and ${ }^{13} \mathrm{C}$ NMR $\left(125 \mathrm{MHz}, \mathrm{DMSO}-d_{6}\right)$, see Table 2 ; HRESIMS $m / z 321.1333[\mathrm{M}+$ $\mathrm{H}]^{+}$(calcd for $\left.\mathrm{C}_{17} \mathrm{H}_{21} \mathrm{O}_{6}, 321.1333\right), m / z 343.1152[\mathrm{M}+\mathrm{Na}]^{+}$(calcd for $\mathrm{C}_{17} \mathrm{H}_{20} \mathrm{O}_{6} \mathrm{Na}, 343.1152$ ).

\subsection{ECD Calculation for Compounds (+)-1, (-)-1, and $\mathbf{3}$}

Monte Carlo conformational searches were carried out by means of the Spartan's 10 software using Merck Molecular Force Field (MMFF). The conformers with Boltzmann-population of over 5\% were chosen for NMR calculations, and then the conformers were initially optimized at B3LYP/6-31G(d,p) level in $\mathrm{MeOH}$ using the CPCM polarizable conductor calculation model. The theoretical calculation 
of ECD was performed in $\mathrm{MeOH}$ using time-dependent density functional theory (TD-DFT) at the B3LYP/6-311+G(d,p) level for all conformers of compounds (+)-1, (-)-1, and 3, respectively. Rotatory strengths for a total of 50 excited states were calculated. ECD spectra were generated using the program SpecDis 1.6 (University of Würzburg, Würzburg, Germany) from dipole-length rotational strengths by applying Gaussian band shapes with sigma $=0.3 \mathrm{eV}$.

\subsection{Antimicrobial Assays}

The antibacterial and antifungal assays were conducted in 96-well plates using a broth micro dilution method [17]. Six pathogenic bacterial strains were used for antibacterial activity, including Staphylococcus epidermidis ATCC 12228, Staphylococcus aureus ATCC 25923, Pseudomonas aeruginosa ATCC 27853, Bacillus cereus ATCC 14579, Escherichia coli ATCC 25922, and Sarcina lutea ATCC 9341. Vancomycin was used as a positive control. Three fungal strains Candida albicans ATCC 10231, Candida tropicalis ATCC 20962, and Candida parapsilosis ATCC 22019 were used for antifungal activity. Amphotericin B was used as a positive control.

\subsection{PTP1B Inhibition Assays}

The PTP1B inhibition assay was performed in 96-well plates [18]. The compound (10 $\mu \mathrm{L})$ was added to the $99 \mu \mathrm{L}$ reaction buffer solution, which consisted of $10 \mathrm{mM}$ Tris (pH 7.4), $50 \mathrm{mM} \mathrm{NaCl}, 2$ $\mathrm{mM}$ dithiothreitol (DTT), $1 \mathrm{mM} \mathrm{MnCl}$, and $10 \mathrm{mM}$ para-nitrophenyl phosphate $(p \mathrm{NPP})$. The reaction mix was pre-warmed using a block heater at $37^{\circ} \mathrm{C}$. The recombinant PTP1B solution $(1 \mathrm{mg} / \mathrm{mL}, 1$ $\mu \mathrm{L})$ was mixed in each well. An $\mathrm{NaOH}$ solution $(10 \mu \mathrm{L}, 0.1 \mathrm{M})$ was added to stop the reaction. The absorbance was recorded at $405 \mathrm{~nm}$ using a microplate. Oleanolic acid was used as a positive control.

\subsection{Cytotoxicity Assays}

The cytotoxic activities were evaluated by the SRB method [19] using five human tumor cell lines A549, HCT116, MCF-7, Hela, and Hep G2. Adriamycin was used as a positive control.

\section{Conclusions}

In summary, the sea hare derived fungus A. terreus RA2905 was effectively induced by chemical epigenetic manipulation with histone deacetylase inhibitor, SAHA, resulting in the isolation of a racemate of benzyl furanone racemate, which further separated chirally as a pair of new enantiomers, and two new benzyl pyrones. The harvested products with the structural features with benzyl furanone or benzyl pyrone skeletons were discovered from natural products for the first time. On the basis of our case, it could be concluded that chemical epigenetic manipulation should be a feasible strategy to activate the silent metabolic pathway and tap new secondary metabolites from marine-derived fungi.

Supplementary Materials: The followings are available online. Figures S1-S20: ${ }^{1} \mathrm{H}$ NMR, ${ }^{13} \mathrm{C}$ NMR, DEPT, HSQC, ${ }^{1} \mathrm{H}-{ }^{1} \mathrm{H}$ COSY, HMBC, and HRESIMS spectra of compounds 1-3, Table S1: The ECD calculation results of (+)-1, (-)-1, and 3, Table S2: The bioactivity assays of isolated compounds.

Author Contributions: Conceptualization, C.-Y.W. and G.-S.Y.; methodology, J.-S.W.; data analysis, J.-S.W., X.-H.S., Y.-H.Z., C.-L.S., and G.-S.Y.; bioassays, J.-S.W., X.-H.S., and G.-S.Y.; writing-original draft preparation, J.-S.W. and X.-H.S.; writing-review and editing, J.-S.W., X.-M.F., X.L., and C.-Y.W. All authors have read and agreed to the published version of the manuscript.

Funding: This research was funded by the National Natural Science Foundation of China (nos. 81673350 and 41830535), the National Science and Technology Major Project for Significant New Drugs Development (no. 2018ZX09735-004), the Education Department of Fujian Province Program (JAT190622), the Min Jiang University program (MYK19011), and the Taishan Scholars Program, China.

Acknowledgments: This paper is in honour of Peter Proksch on his research career to the dedication for his contribution to the marine natural product chemistry. We appreciate the Program of Open Studio for Druggability Research of Marine Natural Products, Pilot National Laboratory for Marine Science and Technology (Qingdao, China) directed by Kai-Xian Chen and Yue-Wei Guo.

Conflicts of Interest: The authors declare no conflict of interest. 


\section{References}

1. Carroll, A.R.; Copp, B.R.; Davis, R.A.; Keyzers, R.A.; Prinsep, M.R. Marine natural products. Nat. Prod. Rep. 2020, 37, 175-223. [CrossRef] [PubMed]

2. Wang, K.W.; Ding, P. New bioactive metabolites from the marine-derived fungi Aspergillus. Mini-Rev. Med. Chem. 2018, 18, 1072-1094. [CrossRef] [PubMed]

3. Lee, Y.M.; Kim, M.J.; Li, H.Y.; Zhang, P.; Bao, B.Q.; Lee, K.J.; Jung, J.H. Marine-derived Aspergillus species as a source of bioactive secondary metabolites. Mar. Biotechnol. 2013, 15, 499-519. [CrossRef] [PubMed]

4. Liu, D.; Li, X.M.; Meng, L.; Li, C.S.; Gao, S.S.; Shang, Z.; Proksch, P.; Huang, C.G.; Wang, B.G. Asperolides A-C, tetranorlabdane diterpenoids from the marine alga-derived endophytic fungus Aspergillus wentii EN-48. J. Nat. Prod. 2011, 74, 1787-1791. [CrossRef] [PubMed]

5. Jillian, R.; Clay, C.C.W. Recent advances in the genome mining of Aspergillus secondary metabolites (covering 2012-2018). Med. Chem. Commun. 2019, 10, 840.

6. Sun, K.L.; Zhu, G.L.; Hao, J.J.; Wang, Y.; Zhu, W.M. Chemical-epigenetic method to enhance the chemodiversity of the marine algicolous fungus, Aspergillus terreus OUCMDZ-2739. Tetrahedron 2018, 74, 83-87. [CrossRef]

7. Xiao, L.; Yin, Y.; Sun, W.; Zhang, F.L.; Li, Z.Y. Enhanced production of (+)-terrein by Aspergillus terreus strain PF26 with epigenetic modifier suberoylanilide hydroxamic acid. Process. Biochem. 2013, 48, 1635-1639. [CrossRef]

8. Chung, Y.M.; Wei, C.K.; Chuang, D.W.; Mohaned, E.S.; Hsieh, C.T.; Asai, T.; Oshima, Y.; Hsieh, T.J.; Hwang, T.L.; $\mathrm{Wu}$, Y.C.; et al. An epigenetic modifier enhances the production of anti-diabetic and anti-inflammatory sesquiterpenoids from Aspergillus sydowii. Bioorg. Med. Chem. 2013, 21, 3866-3872. [CrossRef] [PubMed]

9. Liu, L.; Zheng, Y.Y.; Shao, C.L.; Wang, C.Y. Metabolites from marine invertebrates and their symbiotic microorganisms: Molecular diversity discovery, mining, and application. Mar. Life Sci. Technol. 2019, 1, 60-94. [CrossRef]

10. Zhang, W.; Shao, C.L.; Chen, M.; Liu, Q.A.; Wang, C.Y. Brominated resorcylic acid lactones from the marine-derived fungus Cochliobolus lunatus induced by histone deacetylase inhibitors. Tetrahedron Lett. 2014, 55, 4888-4891. [CrossRef]

11. Chen, M.; Zhang, W.; Shao, C.L.; Chi, Z.M.; Wang, C.Y. DNA methyltransferase inhibitor induced fungal biosynthetic products: Diethylene glycol phthalate ester oligomers from the marine-derived fungus Cochliobolus lunatus. Mar. Biotechnol. 2016, 18, 409-417. [CrossRef] [PubMed]

12. Wu, J.S.; Shi, X.H.; Zhang, Y.H.; Yu, J.Y.; Fu, X.M.; Li, X.; Chen, K.X.; Guo, Y.W.; Shao, C.L.; Wang, C.Y. Co-cultivation with 5-azacytidine induced new metabolites from the zoanthid-derived fungus Cochliobolus lunatus. Front. Chem. 2019, 7, 763. [CrossRef] [PubMed]

13. Wu, J.S.; Yao, G.S.; Shi, X.H.; Rehman, S.U.; Xu, Y.; Fu, X.M.; Zhang, X.L.; Liu, Y.; Wang, C.Y. Epigenetic agents trigger the production of bioactive nucleoside derivatives and bisabolane sesquiterpenes from the marine-derived fungus Aspergillus versicolor. Front. Microbiol. 2020, 11, 85. [CrossRef] [PubMed]

14. Shi, T.; Shao, C.L.; Liu, Y.; Zhao, D.L.; Cao, F.; Fu, X.M.; Yu, J.Y.; Wu, J.S.; Zhang, Z.K.; Wang, C.Y. Terpenoids from the coral-derived fungus Trichoderma harzianum (XS-20090075) induced by chemical epigenetic manipulation. Front. Microbiol. 2020, 11, 572. [CrossRef] [PubMed]

15. Wu, J.S.; Shi, X.H.; Yao, G.S.; Shao, C.L.; Fu, X.M.; Zhang, X.L.; Guan, H.S.; Wang, C.Y. New Thiodiketopiperazine and 3, 4-dihydroisocoumarin derivatives from the marine-derived fungus Aspergillus terreus. Mar. Drugs 2020, 18, 132. [CrossRef] [PubMed]

16. Wang, W.G.; Wang, H.; Du, L.Q.; Li, M.; Chen, L.; Yu, J.; Cheng, G.G.; Zhan, M.T.; Hu, Q.F.; Zhang, L.H.; et al. Matsuda, Y. Molecular basis for the biosynthesis of an unusual chain-fused polyketide, gregatin A. J. Am. Chem. Soc. 2020, 142, 8464-8472. [CrossRef] [PubMed]

17. Clinical and Laboratory Standards Institute (CLSI). Performance Standards for Antimicrobial Susceptibility Testing; Twenty-Second Informational Supplement, M100-S22; Clinical and Laboratory Standards Institute: Wayne, PA, USA, 2012.

18. Tian, J.L.; Liao, X.J.; Wang, Y.H.; Si, X.; Shu, C.; Gong, E.S.; Xie, X.; Ran, X.L.; Li, B. Identification of cyanidin-3-arabinoside extracted from blueberry as a selective protein tyrosine phosphatase $1 \mathrm{~B}$ inhibitor. $J$. Agric. Food Chem. 2019, 67, 13624-13634. [CrossRef] [PubMed] 
19. Skehan, P.; Storeng, R.; Scudiero, D.; Monks, A.; McMahon, J.; Vistica, D.; Warren, J.T.; Bokesch, H.; Kenney, S.; Boyd, K.M.R. New colorimetric cytotoxicity assay for anticancer-drug screening. J. Natl. Cancer 1990, 82, 1107-1112. [CrossRef] [PubMed]

Sample Availability: Samples of the compounds are available from the authors.

(C) 2020 by the authors. Licensee MDPI, Basel, Switzerland. This article is an open access article distributed under the terms and conditions of the Creative Commons Attribution (CC BY) license (http://creativecommons.org/licenses/by/4.0/). 